\title{
Material Disruption
}

\author{
Mary Spyropoulos $^{(\bowtie)}$ and Alisa Andrasek ${ }^{(凶)}$ \\ Royal Melbourne Institute of Technology, Melbourne, Australia \\ s3488461@student.rmit.edu.au, alisa.andrasek@rmit.edu.au
}

\begin{abstract}
This paper examines the role of computational simulation of material processes with robotics fabrication, with the intent of examining its implications for architectural design and construction. Simulation techniques have been adopted in the automotive industry amongst others, advancing their design and manufacturing outputs. At present, architecture is yet to explore the full potential of this technology and their techniques. The need for simulation is evident in exploring the behaviours of materials and their relative properties. Currently, there is a distinct disconnect between the virtual model and its fabricated counterpart. Through research in simulation, we can begin to understand and clearly visualize the relationship between material behaviours and properties that can lead to a closer correlation between the digital design and its fabricated outcome. As the first phase of investigation, the material of clay is used due to its volatile qualities embedded within the material behaviour. The input geometry is constrained to rudimentary extruded forms in order to not obscure the behaviour of the material, but rather allow for it to drive the machine-making process.
\end{abstract}

Keywords: Material behaviour - Material systems · Simulation · Complex geometries $\cdot$ Computation $\cdot$ Additive manufacturing $\cdot$ Robotic fabrication

\section{Context/Introduction}

Currently, architecture is constructed through static modes of inhabitation and engagement originating from the use of the same fundamental materials and construction techniques that were being practiced in the 19th and 20th centuries. In the present-day landscape of the construction sector, there is great potential for innovation through the greater exploration of materiality and embedding big data and new information networks into material-based organized systems of architecture. The expansion into technology enhanced approach aims to challenge the current construction industry, which has become one of the least efficient industries in regard to material usage, material waste and durability. Buildings that are constructed today are being built faster and cheaper as a result of economic competition. The byproduct of this process results in buildings that are more static, material-dense, less durable and less material intelligent then the current technology and knowledge would allow for.

Through collaboration with multidisciplinary research such as material science and advanced manufacturing, this research looks at the specificity of embedding various data systems into material compositions. In conjunction, the notions of integrated fabrication 

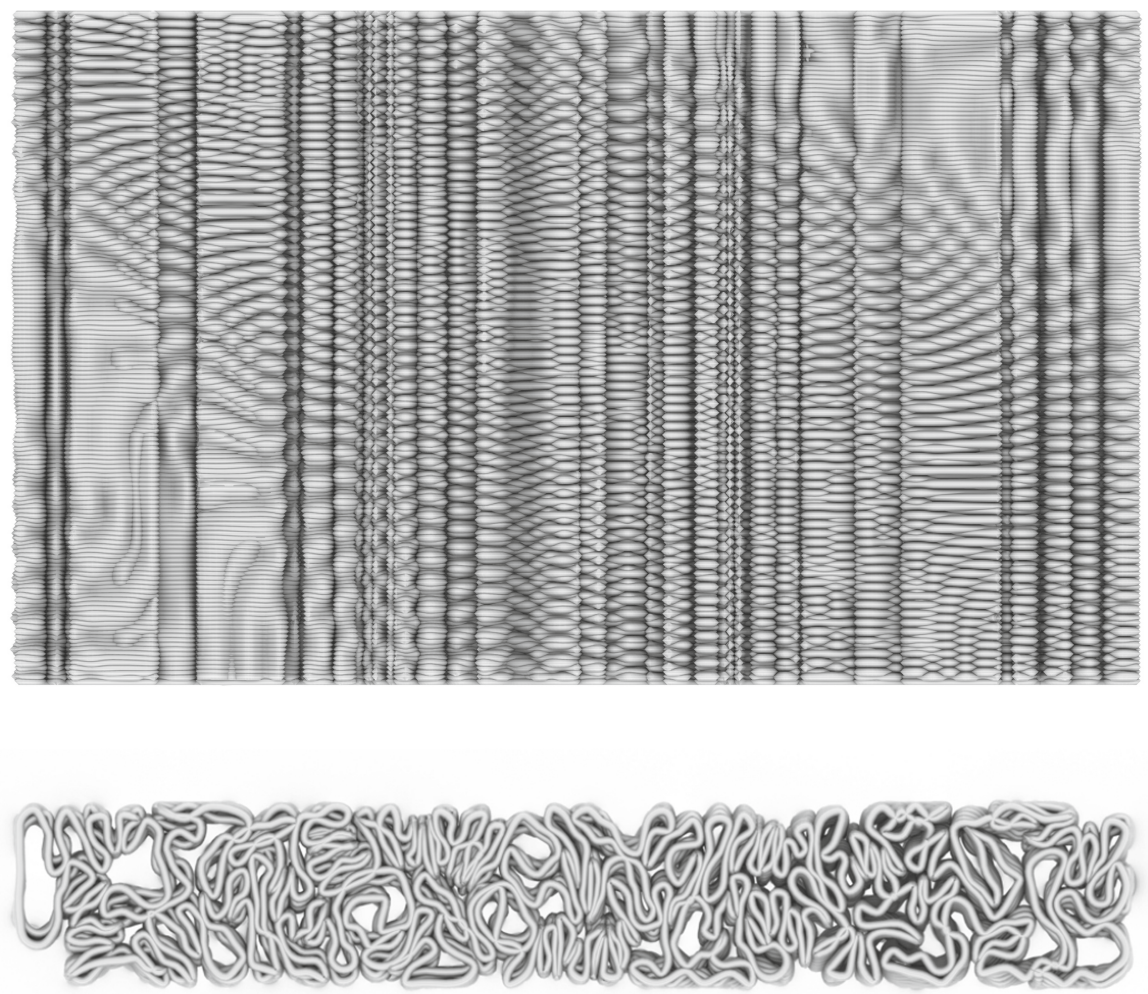

Fig. 1. Wall prototype

techniques, such as robotics and machine vision, will begin to operate in negotiation with materials to evolve fabrication logics and capabilities. This will allow for enriched material palette, with new materials designed by material science in vitro, and existing materials redeployed with novel capacities, for expanded possibilities for architectural applications.

\section{Raw Material Behaviour}

The initial testing for this research sets out to use only constrained rudimentary geometry. This technique is used to privilege the behaviour of the material over a predetermined geometrical form. Minimal cylindrical and rectangular shapes provide an unobscured base for robotic toolpaths. This allows for tracking of qualitative changes in material behavior and uncovering its capacity to be a driver of dominant geometric features. 
Programmability of tool paths allows for variations in speed, rate of extrusion, and extruder nozzle diameter during the robotic printing process. In conjunction to this process tool paths are further manipulated through algorithms that add noise and vibration amplifying the $\mathrm{x}$ and $\mathrm{y}$ axis of the path. Due to the non-linear nature of clay material, each factor contributes to the varying results produced, from initial testing of material behaviour alone.

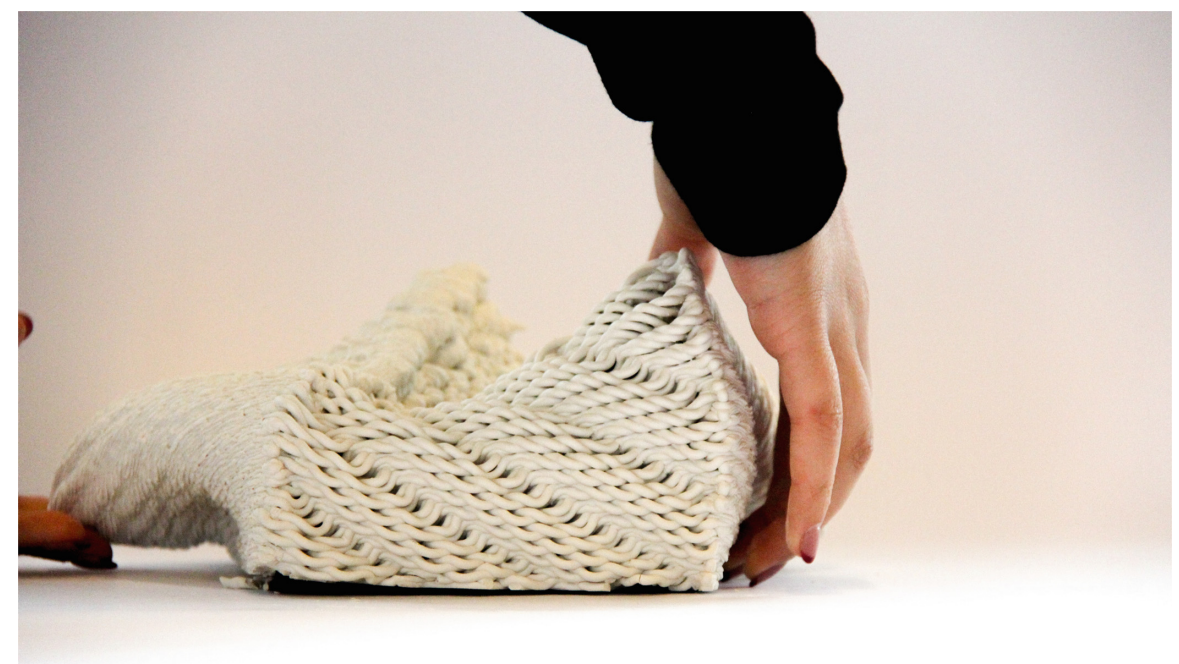

Fig. 2. The collapse

Analysing material behavior resulting from programmable fabrication is providing feedback data for the simulation process. There are many and varying qualitative outcomes embedded within each individual printed outcome. These initial tests provided an insight into the various effects of directionality and slumping which occur through manipulating the toolpaths layer height in conjunction with how fast the robot is printing. Toolpaths were also manipulated through noise algorithms to inform where the deposition of clay would occur. Introducing more algorithmic noise into the toolpath would result in greater material deposition by the robot. This produces emergent qualities of slumping, bulging, weaving and pleating. Tolerance to cantilevering is particularly relevant factor for structural stability. This is particularly evident in Fig. 2 which formed a complete collapse due to pushing the limits of how far the material could support itself when cantilevered.

In less noise manipulated areas directionality is embedded in the printing process through the rate at which the robot would distribute the material. This is due to the consistency in the deposition size which would juxtapose the irregularity in deposition when slumping qualities would occur. This produced differences in scales and density of the patterns due to the varying degree of deposited materials (Fig. 3) 
Newer simulation as per Fig. 1 begins to look at the relationship between density and amplitude to inform how porosity could occur in the typology of a wall. Algorithms were produced to control the growth and variances of pattern in the wall to allow for a distribution and directionality of porous qualities.

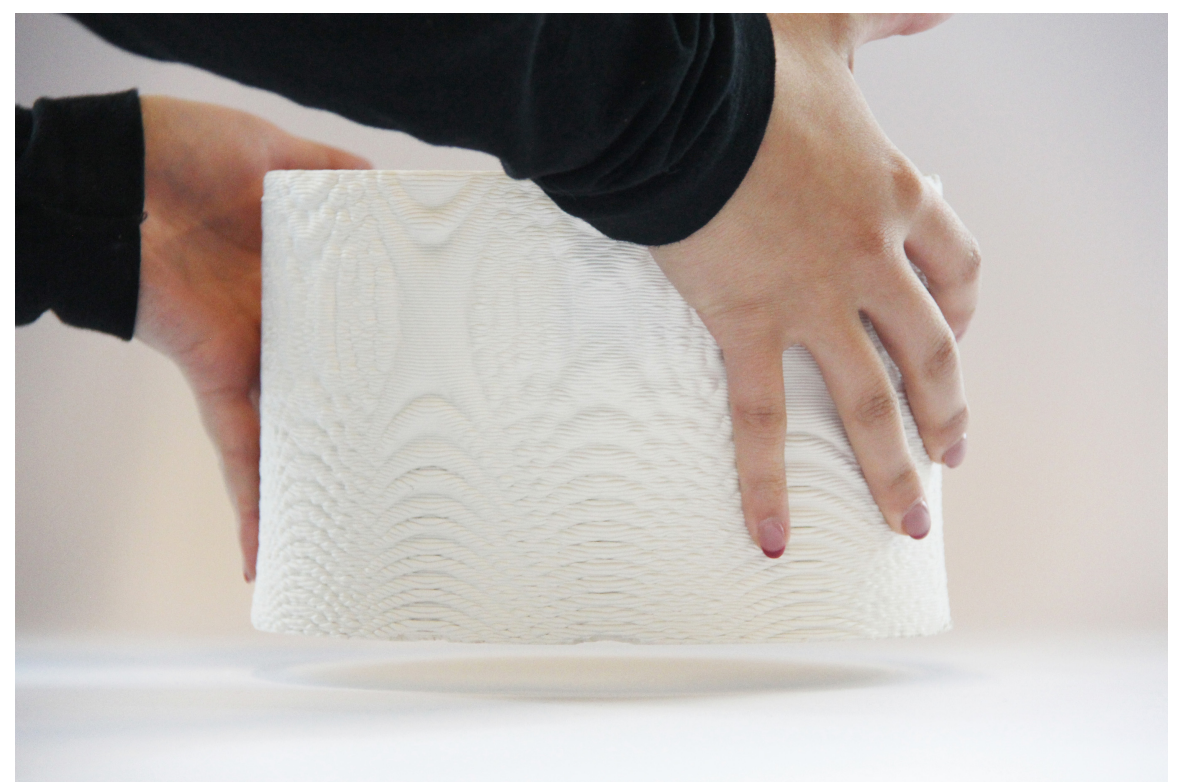

Fig. 3. Noise manipulation

\section{Digital Simulation}

These series of tests form the basis of a feedback loop between robotic fabrication and computational simulation. A series of prototypes allow for investigation of the evolution of the physical material behaviours and its properties. This process provides data and feedback for computational simulation.

Current computational simulation still lacks physics of gravity and friction, and therefore capacity to simulate interaction between the layers. Such abstract and idealized interpretation of material is closer to simulation of less volatile materials such as PLA plastic prints. This in part is due to the volatility and continually varying water levels within the material composition. Water levels are constant contributors to variability, even when mixed with the same ratio, with the time between pugging the mixture, and the external air temperature being the factors with most influence. 


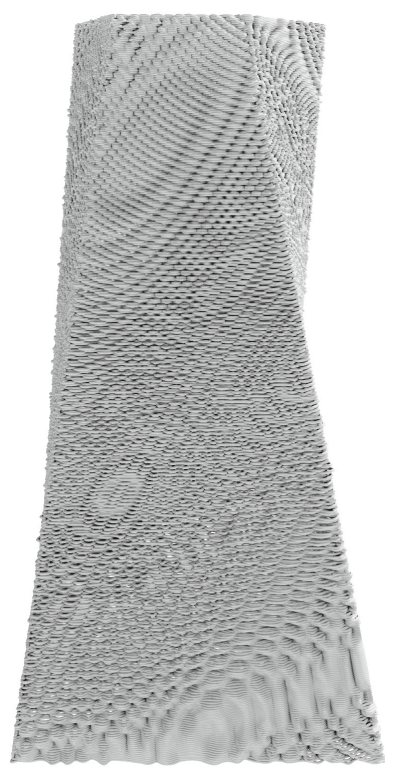

Fig. 4. Digital simulation prototype

By introducing simulation into the process of design, it creates a virtual experience of producing material prototypes. Although prototyping is still something that is inevitable within the process of fabrication and making, we can reduce the number of iterations which are required to be created as physical prototypes. It creates a more streamlined process, although one with more rigorous potential and a greater opportunity for design search in order to truly understand the potential of material behaviors to contribute to the aesthetic, structural, acoustic, thermal and other properties (Figs. 4 and 5). 

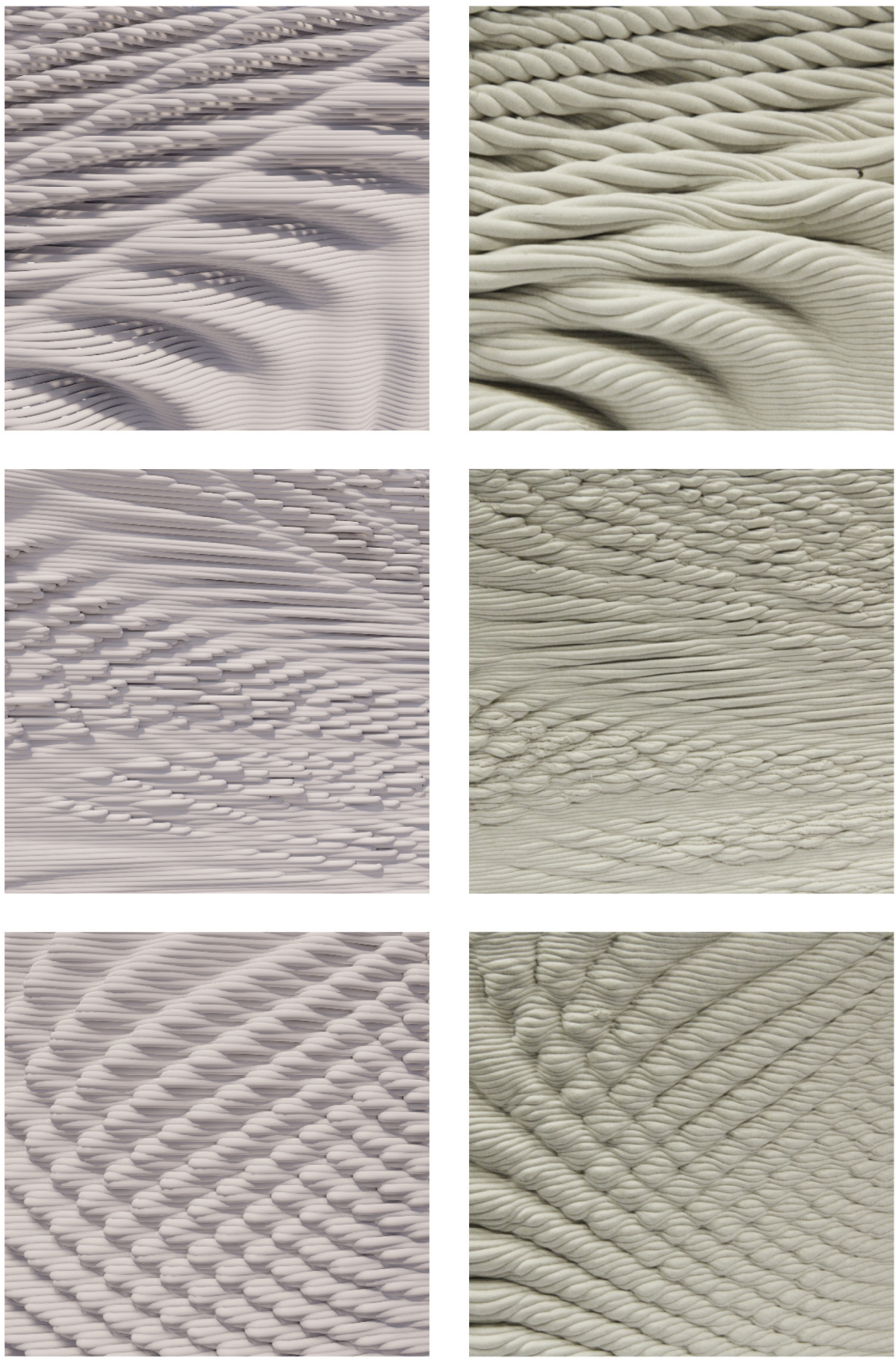

Fig. 5. Comparison of digital simulation and the physical 3D print. 


\section{Conclusion}

Fundamentally, this research proposes the synthesis of material science and advanced fabrication techniques through understanding both physical material properties and its adaptation to computational processes. This allows for a new convergent design and fabrication platform, that can deploy new material compositions within fabric of architecture, while enhancing myriad of performance aspects. Like in the recent automotive industry developments enabled by simulation, big data and machine learning, it can offer radical acceleration in design alternatives, and shortcut physical prototyping time and number of iterations, thus reducing material waste and $\mathrm{CO} 2$ emissions in construction.

Such convergence of material and information ecologies, can enable design of architecture with greatly enhanced performance and novel aesthetics.

\section{References}

1. Manninger, S., del Campo, M.: Plato's columns: platonic geometies vs. vague gestures in robotic construction. In: ACADIA 2017: Disciplines \& Disruption, pp. 374-381 (2017)

2. Carpo, M.: Breaking the curve: big data and design. Artforum, pp. 169-173 (2014)

3. Retsin, G., Garcia, M.J.: Discrete computational methods for robotic additive manufacturing. In: ACADIA 2016: Posthuman Frontiers (2016)

4. Leach, N., Farahi, B., Antonelli, P.: 3D-Printed Body Architecture. Wiley, New York (2017)

5. Menges, A.: Material Synthesis, Fusing the Physical and the Computationa. Wiley, New York (2015)

6. Andrasek, A.: High resolution fabric of architecture, Doctor of Philosophy (PhD), Architecture and Urban Design, RMIT University (2018)

Open Access This chapter is licensed under the terms of the Creative Commons Attribution 4.0 International License (http://creativecommons.org/licenses/by/4.0/), which permits use, sharing, adaptation, distribution and reproduction in any medium or format, as long as you give appropriate credit to the original author(s) and the source, provide a link to the Creative Commons license and indicate if changes were made.

The images or other third party material in this chapter are included in the chapter's Creative Commons license, unless indicated otherwise in a credit line to the material. If material is not included in the chapter's Creative Commons license and your intended use is not permitted by statutory regulation or exceeds the permitted use, you will need to obtain permission directly from the copyright holder.

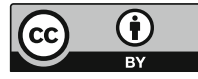

